RESEARCH ARTICLE

\title{
Screen printed Sri Lankan vein graphite/polyaniline composite counter electrode for dye sensitized solar cells
}

\author{
I.P. Perera, S.K.S. Thennakoon and S.S. Gunathilake* \\ Department of Chemistry, Faculty of Science, University of Peradeniya, Peradeniya, Sri Lanka
}

Received: 08/03/2019 ; Accepted: 07/08/2019

\begin{abstract}
Dye sensitized solar cells (DSSCs), described as one of the most prominent third generation solar cells, stand out in the photovoltaic category. In general, DSSCs consist of a large band gap n-type semiconductor electrode (photoanode), a sensitizer (dye), a redox electrolyte, and a counter electrode (CE). A platinized glass substrate is commonly used as the CE which acts as a catalyst for the redox reaction taking place in the cell. Further, it collects electrons from the external load and sends them to the electrolyte. Although Pt has several advantages characteristics, Pt free $\mathrm{CE}$ materials have drawn the attention of researchers because $\mathrm{Pt}$ is an extremely expensive and diminishing noble metal. According to various researches, carbonaceous materials are promising alternatives for the Pt CE. In this study we report the use of Sri Lankan vein graphite/polyaniline (SLVG/PANI) composite as the counter electrode material for DSSCs. Sri Lankan vein graphite (SLVG) is highly crystalline and is a potential low cost alternative to expensive Pt. Polyaniline was prepared by oxidative polymerization of aniline with potassium peroxydisulfate. SLVG/ PANI composites were screen printed on fluorine doped tin oxide (FTO) glass substrate using carboxymethyl cellulose (CMC) as the binder. The performance of the new counter electrode was studied by analyzing the I-V characteristics of the DSSCs and the highest efficiency of $5.0 \%$ was recorded. DSSCs with new counter electrodes were further characterized using powder X-ray diffraction and Fourier Transform Infrared studies.
\end{abstract}

Keywords: Polyaniline, Sri Lankan vein graphite, Composites, Counter electrode, Dye-sensitized solar cells.

\section{INTRODUCTION}

The energy demand with the development of the quality of human life is projected to be increased by $48 \%$ from 2012 - 2040 for a period of 28 years (Cases, 2019). With the depletion of the available fossil fuels and the increment of amount of harmful greenhouse gases emitted into the atmosphere by the combustion of such fossil fuels has led scientists on focusing research upon harvesting energy from renewable energy sources such as wind, tide, geothermal and solar energy (World-nuclear.org., 2019; Anon, 2019).

In comparison with other renewable energy sources, solar energy is the most abundant, constant and least polluting energy source which can be harvested (Panwar, 2011). The amount of energy falling on the surface of the earth from the sun is about $3 \times 10^{24} \mathrm{~J}_{\text {year }}{ }^{-1}$ or $10^{4}$ times the consumption of the world. By covering $0.1 \%$ of earth's area using $10 \%$ efficient solar cells (SCs) would be adequate to meet up the global energy demand (Grätzel, 2005).

Silicon based SCs are the most popular SCs in the market which give efficiencies up to $15-17 \%$ (Lee et al., 2014). Major problem with these SCs are their high manufacturing cost. To use silicon in a SC it must be purified up to $99.9999 \%$ thus making the SC expensive (Braga et al., 2008). Promising solution for the latter problem was given by Gratzel (Grätzel, 2003) with the breakthrough on DSSC challenging Perovskite SCs in higher flexibility, higher transparency and less environmental pollution in addition to being low-cost (O’Regan and Grätzel, 1991,Grätzel, 2003, Deepak et al., 2014). Basic components of DSSCs are, working electrode [n-type $\mathrm{TiO}_{2}$ nanoparticle film deposited on a transparent conducting substanceadsorbed with sensitizer (dye)], redox electrolyte usually $\mathrm{I}^{3-} / \mathrm{I}^{-}$(Boschloo and Hagfeldt, 2009) and counter electrode (CE) which acts as the cathode. CE of DSSC is one of the main components which catalyzes the redox reaction taking place in the cell and it collects electrons from the external load and sends them to the electrolyte. Traditionally Platinum $(\mathrm{Pt})$ is widely used as counter electrode material as it gives high efficiencies. However, since Pt is extremely expensive, diminishing noble metal and decrease in catalytic activity (in long term application) when exposed to corrosive $\mathrm{I}^{3-} / \mathrm{I}^{-}$ redox electrolyte encourage researchers to find alternatives for Pt electrodes (Theerthagiri et al., 2015). Carbonaceous materials such as graphite, graphene, carbon nanotubes, carbon black etc. have grasped attention due to their good electrical conductivity, corrosion resistivity and low-cost (Kouhnavardet al., 2015).

This study reports the use of SLVG/PANI composite as the CE material for DSSCs. Sri Lankan vein graphite is highly crystalline and is a good low-cost material with a good electrical conductivity. Conjugated polymers such as polyaniline (PANI) have been used in organic solar cells due to their excellent electrochemical, optical properties and environmental stability (Han et al., 2014). Unlike all other conducting polymers, the conductivity 
of PANI can be tuned by varying the degree of oxidation (Morsi, Ebrahim and Soliman, 2012).

Emeraldine Base (EB) of PANI is composed of two benzoid units and one quinoid unit alternatively positioned in the polymer chain. Doped EB form of PANI shows electrical conductivity through delocalization of polarons formed on the conjugated polymer chain (de Albuquerque et al., 2004). In this study protonated Emeraldine Base (EB) form of PANI has been used for the fabrication of electrodes, which is the highest conductive form of PANI (Bhadraet al., 2009). Incorporation of additives such as graphite to PANI, has been recorded to enhance its electrical conductivity in literature (Wang et al., 2011). Therefore, the SLVG/PANI composite reported in this study would be a promising alternative counter electrode material for DSSCs with enhanced conductivity, reduced cost and easy fabrication process compared to the conventional $\mathrm{Pt}$ counter electrode.

Many methods such as screen printing, doctor blade, thermal decomposition, electrochemical deposition etc. have been reported to fabricate different counter electrodes for DSSCs (Kumar , 2019, Gomesh, 2015, Hao, 2014, Tsai, 2018). Among them, screen printing method was used for the fabrication of composite electrodes along with a binder, sincethe method results in uniform layer of SLVG/PANI composite on the surface of FTO glass substrates easily. Desired thickness of the active film can be obtained by repeating the printing process several times.

\section{MATERIALS AND METHODS}

\section{Preparation of $\mathrm{TiO}_{2}$ colloidal solution}

Titaniumtetraisopropoxide (TIP) $(20.00 \mathrm{~mL})$, acetic acid $(2.50 \mathrm{~mL})$ and ethanol $(25.00 \mathrm{~mL})$ were mixed and steam was passed through the solution. Rapid hydrolysis of TIP and the expulsion of ethanol by steam produced a transparent $\mathrm{TiO}_{2}$ colloids. Above $\mathrm{TiO}_{2}$ colloids were ground with $5.00 \mathrm{~mL}$ of water in a motar and autoclaved at $150{ }^{\circ} \mathrm{C}$ for three hours.

\section{Preparation of $\mathrm{TiO}_{2}$ spray solution}

Autoclaved solution $(20.00 \mathrm{~mL})$, acetic acid $(5.50 \mathrm{~mL})$, ethanol $(20.00 \mathrm{~mL})$ and 5 drops of Triton X-100 were mixed and sonicated for 10 minutes.

\section{Fabrication of $\mathrm{TiO}_{2}$ on FTO plate}

$\mathrm{TiO}_{2}$ spray solution was sprayed to heated FTO glass plate (Temperature $160{ }^{\circ} \mathrm{C}$ ) with $\mathrm{KM}-150$ spray pyrolysis machine until the film thickness reached about $12 \mu \mathrm{m}$. This plate was sintered at $450{ }^{\circ} \mathrm{C}$ for 30 minutes in air and allowed to cool gradually. The plate was soaked in dye solution [Ruthenium-719 in acetonitrile:tert-butyl alcohol solution (1:1)] at room temperature for 12 hours.

\section{Fabrication of the counter electrode}

\section{Preparation of polyaniline}

Distilled aniline $(10.00 \mathrm{~mL})$ and $1 \mathrm{~mol} \mathrm{dm}^{-3} \mathrm{HCl}(300.0$ $\mathrm{mL})$ were mixed $(1: 30 \mathrm{v} / \mathrm{v} \%)$ and then mixed with 3.00 $\mathrm{g}$ of $\mathrm{K}_{2} \mathrm{~S}_{2} \mathrm{O}_{8}$ which was dissolved in $1 \mathrm{~mol} \mathrm{dm}^{-3} \mathrm{HCl}(100$ $\mathrm{mL}$ ). The solution was stirred for 6 hours using a stirrer and the resultant polyanilne precipitate was filtered. Polyaniline precipitate was washed using three $100 \mathrm{~mL}$ portions of 0.5 $\mathrm{mol} \mathrm{dm}{ }^{-3} \mathrm{HCl}$ followed by acetone and dried in a desiccator for 12 hours.

\section{Preparation of SLVG/PANI composite slurry for screen printing}

Different mass ratios of Sri Lankan vein graphite and polyaniline (w/w \%) were mixed thoroughly in a motar using a pestle. $10 \%(\mathrm{w} / \mathrm{w} \%)$ carboxymethyl cellulose (CMC) was added which was dissolved in minimum

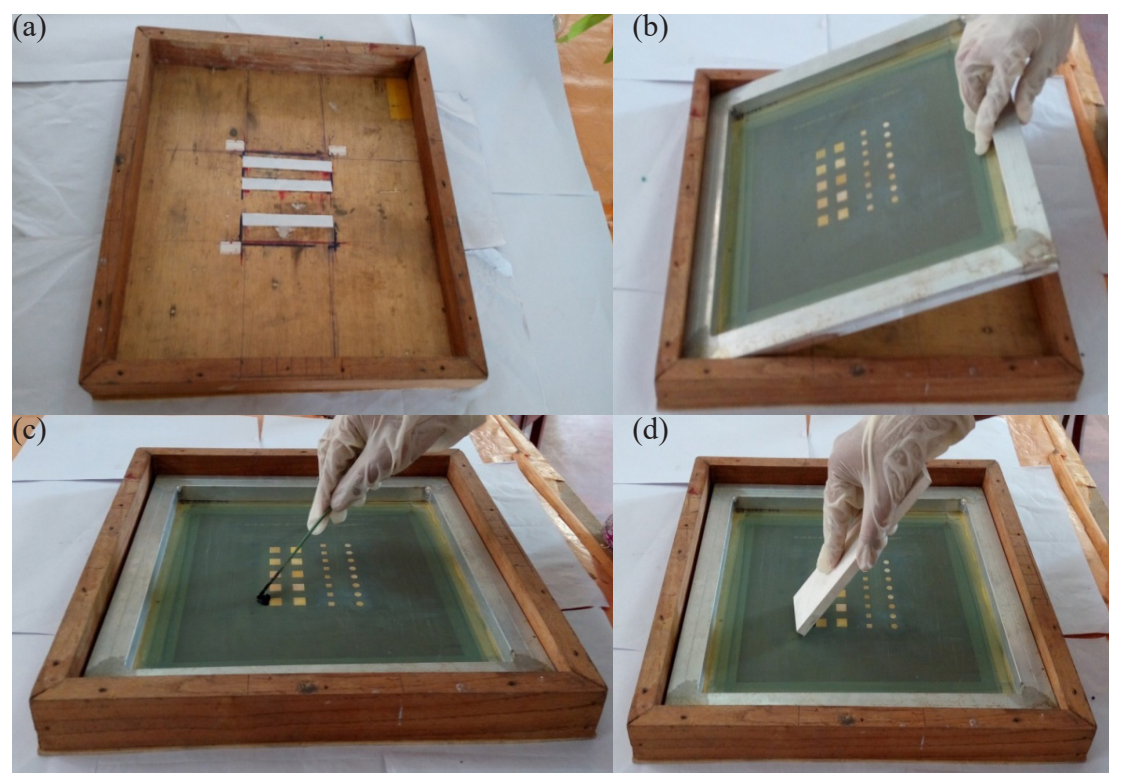

Figure 1: Steps followed in screen printing method; (a) mount FTO glass was inside the frame, (b) place the screen, (c,d) place the slurry on the screen. 
amount of distilled water along with 1 drop of Triton X-100, and mixed thoroughly in the motar, next the mixture was heated to $60{ }^{\circ} \mathrm{C}$ until a slurry was obtained.

\section{Screen printing of SLVG/PANI composite}

Screen printing was done on cleaned FTO glasses using the above prepared slurry. Screen printing process was done several times till the desired thickness of the electrode was achieved. First the FTO glass was mounted inside the frame using double sided glue tape [Figure 1(a)]. Then the screen was carefully placed on top of the FTO glass as shown in the Figure1 (b). Next the prepared slurry was placed on the screen as shown in Figure 1 (c). The slurry was printed on FTO glass substrate as a uniform layer in the screen using a squeegee as shown in the Figure 1 (d). This process was done repeatedly until the desired thickness is obtained on the FTO glass.

\section{Fabrication of DSSC}

Few drops of electrolyte was sandwiched in between fabricated working electrode and the counter electrode using clippers and the photo voltaic measurements were taken by connecting those electrodes to the solar simulator.

\section{Characterization of SLVG/PANI composite}

Synthesized PANI and SLVG/PANI composites were characterized using Powder X-ray Diffraction (PXRD), Scanning Electron Microscopy (SEM) and Fourier Transform Infrared Spectroscopy (FITR).

\section{RESULTS AND DISCUSSION}

EB form of PANI, the structure is consisted of equal proportions of amines $(-\mathrm{NH}-)$ and imine $(=\mathrm{N}-)$ sites. Protonic acids used during the synthesis are capable of protonating the imine sites creating a bipolaron (Stafström et al., 1987). The resultant bipolaron then undergoes further rearrangements to form the delocalized polaron lattice enabling the conductivity of PANI. The resulting emeraldine salt (ES) has conductivity on a semiconductor level of the order of $100 \mathrm{~S} \mathrm{~cm}^{-1}$ (Bhadra et al., 2009). A suitable binder for the screen printing process was selected using the trial and error method. The binders tested for the screen printing process were carboxymethylcellulose (CMC) and poly(ethylene glycol) (PEG). PEG did not show promising characteristics as a binder since the counter electrode materials including PANI, SLVG and PANI/SLVG composites were tend to peel off with PEG upon introducing the liquid electrolyte. This could have been overcome by employing high temperature, however, sintering was not done during the fabrication, since there is a possibility of polymer degradation at high temperatures. On the other hand, CMC showed promising binding capabilities between the developed counter electrode materials and FTO glass substrate even at room temperature. The film was stable upon introducing the liquid electrolyte. CMC could increase the binding capability by acting as an intermediate between PANI/SLVG and FTO substrate. The strong binding between CMC and both the counter electrode material (PANI/SLVG) and FTO glass substrate can be expected through hydrogen bonding because of the presence of many hydroxyl groups on $\mathrm{CMC}, \mathrm{N}-\mathrm{H}$ groups on PANI and oxygen atoms on FTO coating $\left(\mathrm{SnO}_{2}\right)$. It has been reported in literature that the oxygen atoms in hydroxyl groups in CMC can strongly interact with amine groups in polyaniline forcing its molecules to align along (Jayanty et al., 2015). In addition to the strong binding capability, due to aligning of the PANI molecules, it is stated that CMC leads to a more ordered chain which results in better conductivity, since these arrangement of molecules flatten the structure of molecule in the region of delocalization occurs. However, upon increasing the CMC amount, the conductivity of the counter electrode exponentially decreased due to insulating properties of the binder CMC.

\section{Characterization of SLVG/PANI composite by PXRD analysis}

When considering the diffraction pattern of pure SLVG which is shown in Figure 2 (b), two distinguishable peaks at $2 \theta=26.52^{\circ}$ and $2 \theta=54.61^{\circ}$ are corresponding to $(00$ 2) and $\left(\begin{array}{lll}1 & 1 & 0\end{array}\right)$ planes of graphite respectively. Since PANI has an amorphous character, distinguishable peaks are not observed in the diffraction pattern which is shown in Figure 2 (a), only a broad peak centered around $30^{\circ}$ was observed. The peaks of $2 \theta=26.52^{\circ}$ and $2 \theta=54.61^{\circ}$ of graphite are clearly visible in the diffraction pattern of SLVG/PANI composite which is shown in Figure 3.2 (c). Although the relative intensities of peaks of graphite in the SLVG/PANI composite are low compared with that of the neat graphite upon composite formation, the presence of the peaks (a)

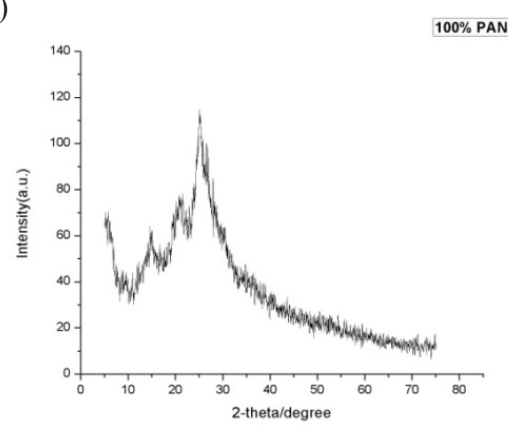

(b)

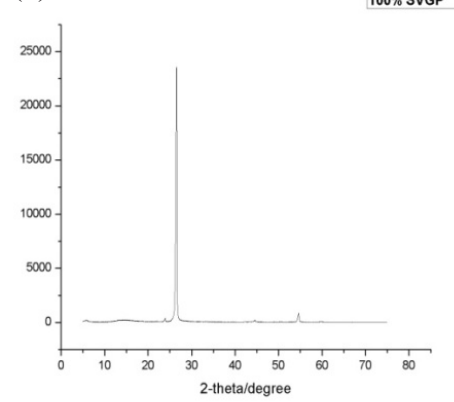

(c)

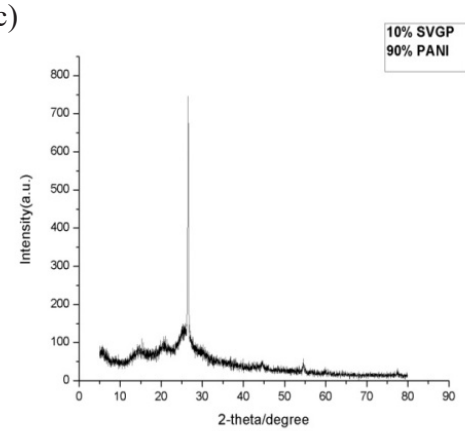

Figure 2:PXRD patterns of (a) 100\% PANI (b) 100\% SLVG (c) 10\%/90\% SLVG/PANI composite 
of SLVG confirms that SLVG has retained its structure even though it is dispersed in PANI. Further, broad peaks observed in pure PANI were also observed in SLVG/PANI composite indicating the formation of composite.

\section{Characterization of SLVG/PANI composite by SEM Analysis}

SEM analysis was carried out on pure PANI, pure SLVG and SLVG/PANI (10\%/90\%) composite which were screen printed on FTO glasses using CMC in order to study the variation of the morphology of the counter electrode surface. The composition 10\%/90\% SLVG/PANI was selected as this composition gave the best efficiency of $5.0 \%$ in DSSCs fabricated (Table 1). According to the above SEM images the plate like surface morphology of graphite [Figure 3 (b)] has been transformed into a porous structure as in the pure PANI [Figure 3 (a)] upon the composite [Figure 3 (c)] formationby indicating the distribution of SLVG in PANI during the composite preparation. Furthermore, catalytic activity of the counter electrode can be explained by the high surface area of the composite which is due to the porous structure given by the composite. According to SEM images, the average particle size of SLVG and PANI are $2.05 \mu \mathrm{m}$ and $1.58 \mu \mathrm{m}$ respectively, while the particle size has been reduced to $0.95 \mu \mathrm{m}$ upon the preparation of the PANI/SLVG composite. This reflects that the reduction in particle size also enables a high surface area for the adsorption of the liquid electrolyte in the counter electrode surface.

\section{FT-IR Analysis of SLVG/PANI composites}

FT-IR analysis was carried out for different ratios of
SLVG/PANI composites in order to find the functional groups present in the composites and the spectra are shown in Figure 4. Further, FT-IR analysis on pure PANI was used to confirm the formation of the PANI by chemical polymerization method. When considering FT-IR spectrum of the $100 \%$ PANI it clearly indicates two characteristic peaks of PANI around at $3400 \mathrm{~cm}^{-1}$ and $1200 \mathrm{~cm}^{-1}$. Peak around $3400 \mathrm{~cm}^{-1}$ is due to the N-H stretching of $-\mathrm{NH}$ functional group while peak around $1195 \mathrm{~cm}^{-1}$ may refer to $\mathrm{C}-\mathrm{N}$ stretching of secondary amine. The peaks at $1512 \mathrm{~cm}^{-1}$ and $1624 \mathrm{~cm}^{-1}$ correspond to the benzenoid and quinoid vibrations of PANI (Nikzad et al., 2009). From the FT-IR spectrum of $100 \%$ PANI, it can be predicted that PANI has been formed. Those characteristic peaks discussed above are depleted in intensity upon increasing the graphite ratio, indicating that the composition of the composites has been varied as intended.

\section{Photo current-voltage characteristics (I-V curves)}

$\mathrm{I}-\mathrm{V}$ curves were plotted for each measurement taken for the fabricated solar cells with $\mathrm{I}^{-} / \mathrm{I}^{3-}$ redox mediator and their performances were investigated. Pt electrode wass used as the standard counter electrode for the comparison with the fabricated SLVG/PANI counter electrode as a substitute for the Pt electrode.

The current-voltage (I-V) characteristics of the cells at AM $1.5\left(100 \mathrm{~mW} \mathrm{~cm}^{-2}\right)$ simulated sunlight irradiation with an active area of $1.0 \mathrm{~cm}^{2}$ were recorded with a calibrated solar-cell evaluation system (PECCELL PEC-L01) solar stimulator.
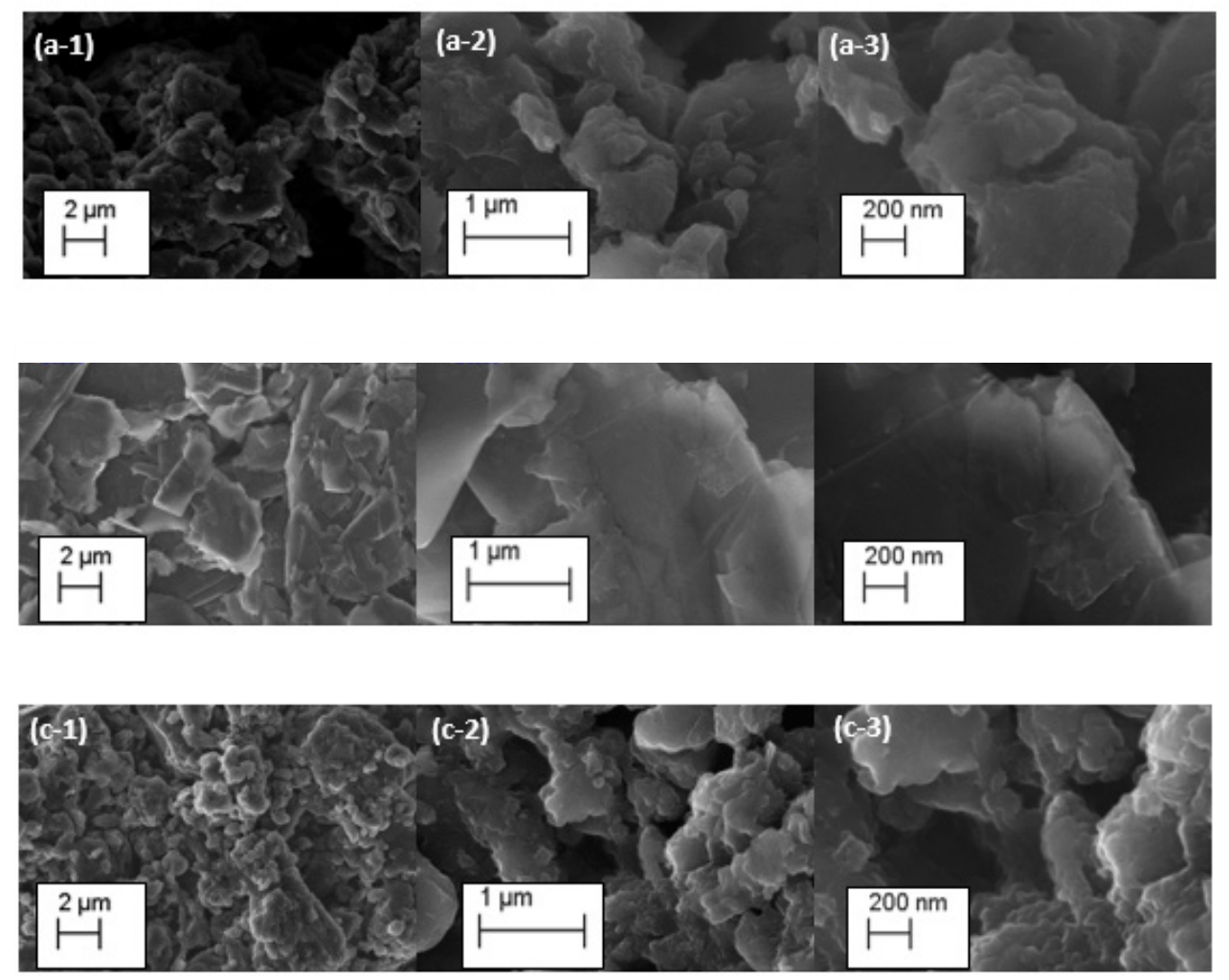

Figure 3: SEM images of (a) 100\% PANI (b) 100\% SLVG (c) 10\%/90\% SLVG/PANI composite. 


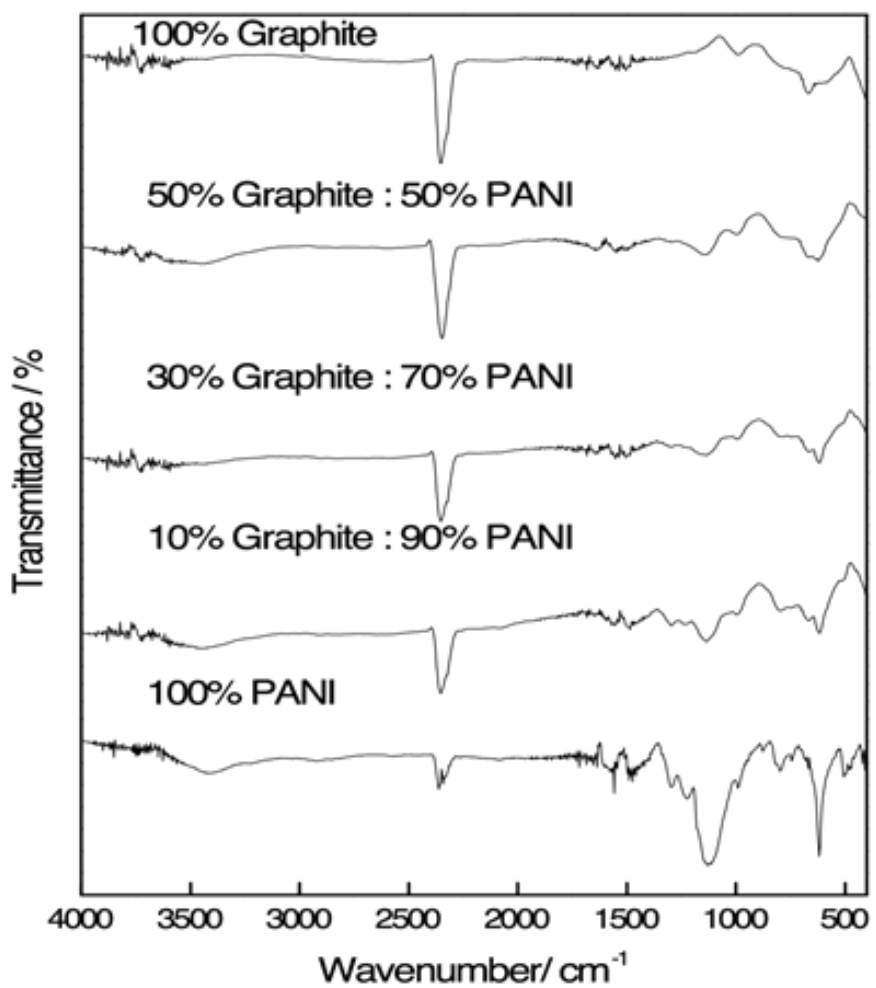

Figure 4: FT-IR spectra of different ratios of SLVG/PANI composites.

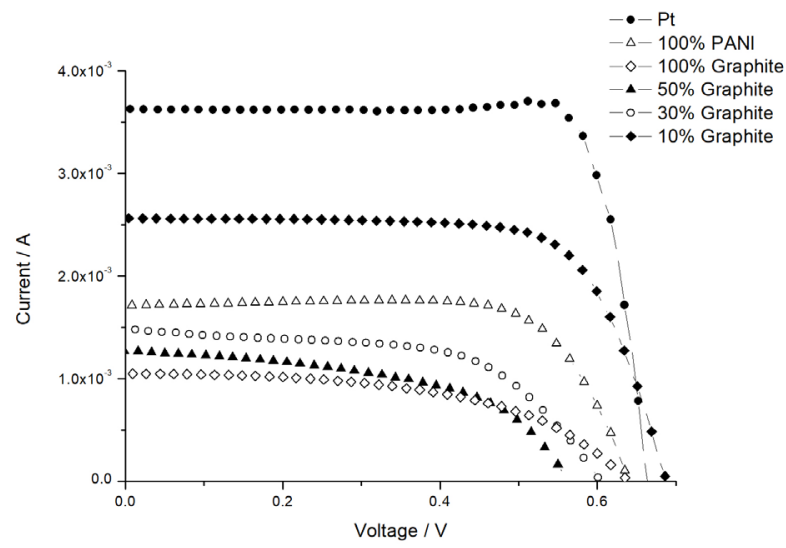

Figure 5: Photocurrent-voltage characteristics with different Graphite/PANI ratios and standard Pt electrode.

Table 1: Photocurrent-voltage characteristics with different Graphite:PANI ratios compared to Pt counter.

\begin{tabular}{|c|c|c|c|c|}
\hline Counter Electrode & $\begin{array}{l}V_{o c} \\
m V\end{array}$ & $\begin{array}{c}J_{S C} \\
m A \mathrm{~cm}^{-2}\end{array}$ & $F F / \%$ & $\eta / \%$ \\
\hline $\mathrm{Pt}$ & 663 & 14.5 & 84.0 & 8.1 \\
\hline 0:100 (SLVG:PANI) & 641 & 6.8 & 74.0 & 3.2 \\
\hline 10:90 (SLVG:PANI) & 688 & 10.2 & 72.0 & 5.0 \\
\hline 30:70 (SLVG:PANI) & 605 & 5.9 & 58.0 & 2.1 \\
\hline 50:50 (SLVG:PANI) & 563 & 5.1 & 52.0 & 1.5 \\
\hline 100:0 (SLVG:PANI & 638 & 4.2 & 53.0 & 1.4 \\
\hline
\end{tabular}

* The maximum values are reported out of five cells tested from each type 
As can be seen from Figure 5 and Table 1, the maximum efficiency was observed with the counter electrode with SLVG/PANI 10:90 (w/w \%) composite. Efficiency of the DSSC with 10:90 composite increases compared to the DSSC with pure PANI because of the high electrochemical activity of SLVG. According to previous research done on graphite/polyaniline composites, the conductivity of the composite increases upon increasing the amount of graphite in the composite (Wang et al., 2011). However, the results of this study indicate that the efficiency of the DSSC decreases when the graphite content is increased. This may be because of the disordered transmission pathways of electrons as the SLVG content increases beyond the optimum value.

\section{CONCLUSIONS}

In conclusion, SLVG/PANI composite can be considered as a promising material to be used as a counter electrode in DSSC. The composite can be successfully prepared by blending SLVG and PANI synthesized by chemical oxidative polymerization. The counter electrode fabricated on FTO glass substrate by screen printing method with 1:9 $(\mathrm{w} / \mathrm{w})$ ratio of SLVG:PANI showed a maximum efficiency of $5.0 \%$ with $688 \mathrm{mV}$ open circuit voltage, $10.2 \mathrm{~mA} \mathrm{~cm}^{-2}$ current density and 72.0 fill factor.

\section{REFERENCES}

Anon. (2019). [online] Available at: http://www.ren21.net/ Portals/0/documents/Resources/GSR/2014/GSR2014 full\%20report_low\%20res.pdf, 2016. [Accessed 19 Feb. 2019].

Bhadra, S., Khastgir, D., Singha, N. and Lee, J. (2009) Progress in preparation, processing and applications of polyaniline. Progress in Polymer Science, 34(8): 783810.

Boschloo, G. and Hagfeldt, A. (2009).Characteristics of the Iodide/Triiodide Redox Mediator in Dye-Sensitized Solar Cells. Accounts of Chemical Research, 42(11): 1819-1826.

Braga, A., Moreira, S., Zampieri, P., Bacchin, J. and Mei, P. (2008). New processes for the production of solargrade polycrystalline silicon: A review. Solar Energy Materials and Solar Cells, 92(4): 418-424.

Cases, E. (2019). EIA's AEO2017 projects the United States to be a net energy exporter in most cases. [online] Ajot. com. Available at: https://www.ajot.com/news/eiasaeo2017-projects-the-united-states-to-be-a-net-energyexporter-in-most [Accessed 19 Feb. 2019].

De Albuquerque, J., Mattoso, L., Faria, R., Masters, J. and MacDiarmid, A. (2004).Study of the interconversion of polyaniline oxidation states by optical absorption spectroscopy. Synthetic Metals, 146(1): 1-10.

Gomesh N., Ibrahim A.H., Syafinar R., Irwanto M., Mamat M.R., Irwan Y.M, Hashim U. and Mariun N. (2015) Fabrication Of Dye Sensitized Solar Cell Using Various Counter Electrode Thickness, International Journal Series in Engineering Science, 1(1): 49-56.

Grätzel, M. (2005).Solar Energy Conversion by DyeSensitized Photovoltaic Cells. Inorganic Chemistry, 44(20): 6841-6851.
Grätzel, M. (2003). Dye-sensitized solar cells. Journal of Photochemistry and Photobiology C: Photochemistry Reviews, 4(2): 145-153

Han, G., Liu, Y., Zhang, L., Kan, E., Zhang, S., Tang, J. and Tang, W. (2014). $\mathrm{MnO}_{2}$ Nanorods Intercalating Graphene Oxide/Polyaniline Ternary Composites for Robust High-Performance Supercapacitors. Scientific Reports, 4(1)

Hao N.T.Q. (2014) Fabrication of Platinum Nanoparticle Counter Electrode for Highly Efficient Dye-sensitized Solar Cells by Controlled Thermal Reduction Time, Journal of Materials Science, 49.

Jayanty S., (2015) Carboxy methyl cellulosetemplated polyaniline: Film Morphology and Conductivity, International Journal of Energy, Sustainability and Environmental Engineering, 1(4-5), 123-127.

Kouhnavard, M., Ludin, N., Ghaffari, B., Sopian, K. and Ikeda, S. (2015). Carbonaceous Materials and Their Advances as a Counter Electrode in Dye-Sensitized Solar Cells: Challenges and Prospects. ChemSusChem, 8(9), pp.1510-1533.

Kumar K.D., Swami S.K., Dutta V.,Chen B., Bennett N. and Upadhyaya H.M. (2019). Scalable screen-printing manufacturing process for graphene oxide platinum free alternative counter electrodes in efficient dye sensitized solar cells, FlatChem, 100105.

Lee, Y., Kim, B., Ifitiquar, S., Park, C. and Yi, J. (2014). Silicon solar cells: Past, present and the future. Journal of the Korean Physical Society, 65(3), pp.355-361.

Morsi, I., Ebrahim, S. and Soliman, M. (2012) Construction and Study of Hetreojunction Solar Cell Based on Dodecylbenzene Sulfonic Acid-Doped Polyaniline/nSi.International Journal of Photoenergy, 1-6.

Nikzad, L., Alibeigi, S., Vaezi, M., Yazdani, B. and Rahimipour, M. (2009). Synthesis of a GraphitePolyanilineNanocomposite and Evaluation of Its Electrochemical Properties. Chemical Engineering \& Technology, 32(6): 861-866.

O’Regan, B. and Grätzel, M. (1991). A low-cost, highefficiency solar cell based on dye-sensitized colloidal $\mathrm{TiO}_{2}$ films. Nature, 353(6346): 737-740.

Panwar N.L., Kaushik S.C., Kothari S., (2011) Role of renewable energy sources in environmental protection: A review. Renewable and sustainable energy reviews, 1513-1524.

Stafström, S., Brédas, J., Epstein, A., Woo, H., Tanner, D., Huang, W. and MacDiarmid, A. (1987). Polaron lattice in highly conducting polyaniline: Theoretical and optical studies. Physical Review Letters, 59(13): 14641467.

Theerthagiri, J., Raja Senthil,, A., Madhavan, J. and Maiyalagan, T. (2015). Recent Progress in NonPlatinum Counter Electrode Materials for DyeSensitized Solar Cells. ChemElectroChemreviews. [online]Availableat:https://www.researchgate.net/ profile/J_Theerthagiri/publication/275103200_ Recent_Progress_in_Non-Platinum_Counter_ Electrode_Materials_for_Dye-Sensitized_Solar_Cells/ links/5abc841ba6fdcccda6561ba7/Recent-Progress-inNon-Platinum-Counter-Electrode-Materials-for-Dye- 
Sensitized-Solar-Cells.pdf [Accessed 19 Feb. 2019].

Thomas, S., Deepak, T., Anjusree, G., Arun, T., Nair, S. and Nair, A. (2014). A review on counter electrode materials in dye-sensitized solar cells. J. Mater. Chem. A, 2(13): 4474-4490.

Tsai, C.H., Hsiao, Y.C. and Chuang, P.Y. (2018) Investigation of Electrochemically Deposited and Chemically Reduced Platinum Nanostructured Thin Films as Counter Electrodes in Dye-Sensitized Solar Cells, Coatings, 8: 56
Wang, L., Wang, D., Zhu, G., Li, J. and Pan, F. (2011) Thermoelectric properties of conducting polyaniline/ graphite composites. Materials Letters, 65(7): 10861088.

World-nuclear.org. (2019). Renewable Energy and Electricity | Sustainable Energy | Renewable Energy - World Nuclear Association. [online] Available at: http://www.world-nuclear.org/information-library/ energy-and-the-environment/renewable-energy-andelectricity.aspx [Accessed 19 Feb. 2019]. 